\title{
Modeling Hydrofluoroolefins with the Cubic Plus Association and Perturbed-Chain Statistical Associating Fluid Theory Equations of State
}

\author{
Kang, Kai; Wang, Xiaopo; Kontogeorgis, Georgios M.; Liang, Xiaodong
}

Published in:

Industrial and Engineering Chemistry Research

Link to article, DOI:

10.1021/acs.iecr.8b04813

Publication date:

2018

Document Version

Peer reviewed version

Link back to DTU Orbit

Citation (APA):

Kang, K., Wang, X., Kontogeorgis, G. M., \& Liang, X. (2018). Modeling Hydrofluoroolefins with the Cubic Plus Association and Perturbed-Chain Statistical Associating Fluid Theory Equations of State. Industrial and Engineering Chemistry Research, 57, 17289-17300. https://doi.org/10.1021/acs.iecr.8b04813

\section{General rights}

Copyright and moral rights for the publications made accessible in the public portal are retained by the authors and/or other copyright owners and it is a condition of accessing publications that users recognise and abide by the legal requirements associated with these rights.

- Users may download and print one copy of any publication from the public portal for the purpose of private study or research.

- You may not further distribute the material or use it for any profit-making activity or commercial gain

- You may freely distribute the URL identifying the publication in the public portal 


\title{
Thermodynamics, Transport, and Fluid Mechanics
}

Subscriber access provided by DTU Library

\section{Modeling Hydrofluoroolefins with the CPA and PC-SAFT Equations of State}

\author{
Kai Kang, Xiaopo Wang, Georgios M. Kontogeorgis, and Xiaodong Liang
}

Ind. Eng. Chem. Res., Just Accepted Manuscript • DOI: 10.1021/acs.iecr.8b04813 • Publication Date (Web): 20 Nov 2018

Downloaded from http://pubs.acs.org on November 20, 2018

\section{Just Accepted}

"Just Accepted" manuscripts have been peer-reviewed and accepted for publication. They are posted online prior to technical editing, formatting for publication and author proofing. The American Chemical Society provides "Just Accepted" as a service to the research community to expedite the dissemination of scientific material as soon as possible after acceptance. "Just Accepted" manuscripts appear in full in PDF format accompanied by an HTML abstract. "Just Accepted" manuscripts have been fully peer reviewed, but should not be considered the official version of record. They are citable by the Digital Object Identifier (DOI@). "Just Accepted" is an optional service offered to authors. Therefore, the "Just Accepted" Web site may not include all articles that will be published in the journal. After a manuscript is technically edited and formatted, it will be removed from the "Just Accepted" Web site and published as an ASAP article. Note that technical editing may introduce minor changes to the manuscript text and/or graphics which could affect content, and all legal disclaimers and ethical guidelines that apply to the journal pertain. ACS cannot be held responsible for errors or consequences arising from the use of information contained in these "Just Accepted" manuscripts. 


\title{
Modeling Hydrofluoroolefins with the CPA and PC- SAFT Equations of State
}

\author{
Kai Kang ${ }^{a, b}$, Xiaopo Wang $^{b}$, Georgios M. Kontogeorgis ${ }^{a}$, Xiaodong Liang ${ }^{a *}$ \\ ${ }^{a}$ Center for Energy Resources Engineering (CERE), Department of Chemical and Biochemical \\ Engineering, Technical University of Denmark, DK-2800 Kgs. Lyngby, Denmark \\ ${ }^{\mathrm{b}}$ MOE Key Laboratory of Thermo-Fluid Science and Engineering, School of Energy and Power \\ Engineering, Xi'an Jiaotong University, No. 28, Xianning West Road, Xi’an, P. R. China \\ KEYWORDS: HFOs (hydrofluoroolefins), CPA, PC-SAFT, parameter estimation, derivative \\ properties
}




\begin{abstract}
Hydrofluoroolefins (HFOs) have been proposed as promising candidates for alternative refrigerants. In this work, a comprehensive comparison of the performance of the Cubic Plus Association (CPA) and (Perturbed-chain SAFT) (PC-SAFT) equations of state for six thermodynamic properties of HFOs is presented, in which eleven parameter estimation methods are considered and analyzed. Based on the comparison with experimental data and a theoretical analysis, a method meeting both satisfactory results and simplicity is recommended for parameter estimation for this type of compounds. The results show that both CPA and PC-SAFT perform equally well for the prediction of vapor pressure, liquid density and speed of sound in gas phase. CPA provides better isobaric heat capacity predictions compared to PC-SAFT irrespectively of the estimation method used but PC-SAFT presents the best overall performance when all properties are considered.
\end{abstract}




\section{Introduction}

Refrigerants are widely used in a variety of heating, ventilation, air conditioning, and refrigeration equipment. Hydrofluorocarbons (HFCs), as the most common refrigerants nowadays, have zero ozone depletion potential (ODP). However, they are also characterized by their substantial global warming potential (GWP) value when released to the atmosphere. The growing international attention on global warming mitigation has stimulated interest in a new generation of low-GWP refrigerants. Consequently, a global environmental deal was signed in 2016 to phase out productions and consumption of HFCs during the period 2036 to 2047, starting from 2019. In order to meet this demand, the National Institute of Standards and Technology (NIST) recommended a list of potential viable refrigerants, which are expected to have lower values of GWP based on the chemical structure, the radiative efficiency, and the atmosphere lifetime of these molecules ${ }^{1}$. HFOs were included in NIST's recommendation list as the most promising emerging alternative refrigerants.

Reliable values of thermodynamic properties are essential for designing and evaluating the refrigeration cycle performance. Much research on HFOs is already available, including experimental measurements of various properties $2,3,12-21,4,22-29,5-11$ and modeling, but much more work is needed in both directions. We have in this work collected experimental data from literature for a variety of properties (including vapor pressure, liquid density, isobaric heat capacity and speed of sound) of six common HFOs (with structures shown in Figure 1). The data are summarized in Table 1. Due to lack of data of R1234zf and R1225ye(Z), these two compounds are not considered in depth in this study, but they are kept in Figure 1 and Table 1 as reference for future investigations. 

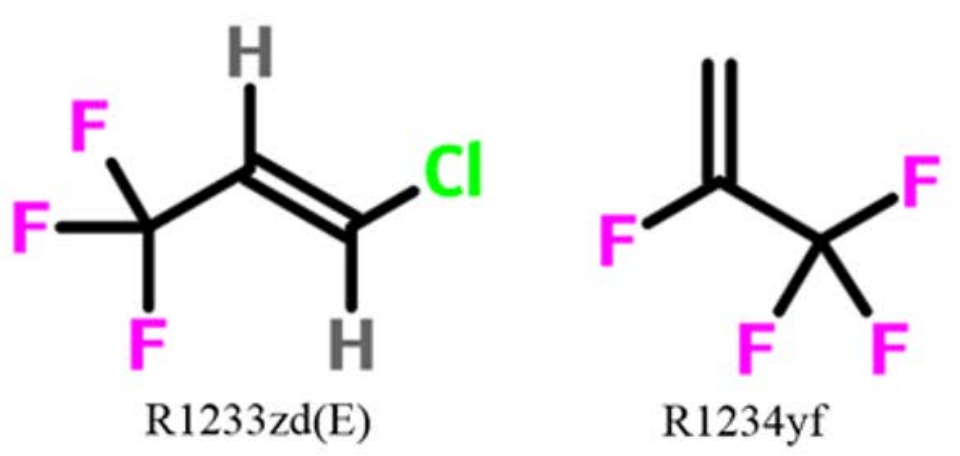

R1234yf

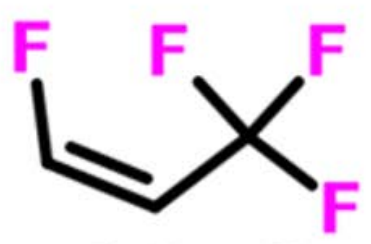

R1234ze(Z)

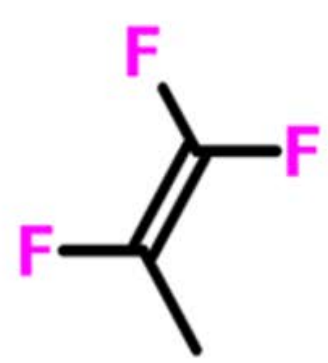

R1243zf

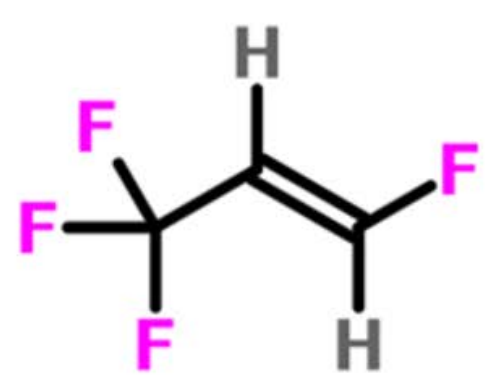

R1234ze(E)

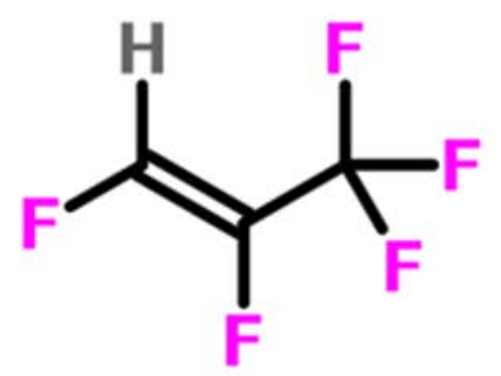

R1225ye(Z)

Figure 1. The structures of the six HFOs considered in this work. 1-Chloro-3, 3,3-trifluoropropene (R1233zd(E)), 2,3,3,3-Tetrafluoropropene (R1234yf), trans 1,3,3,3-tetrafluoropropene (R1234ze(E)), cis 1,3,3,3-tetrafluoropropene (R1234ze(Z)), 3,3,3-trifluoroprop-1-ene (R1243zf), and cis-1,2,3,3,3-Pentafluoroprop-1-ene (R1225ye(Z)).

Table 1. Summary of Experimental Data for Six Pure HFO Components*

\begin{tabular}{|c|c|c|c|c|c|c|c|}
\hline Compound & Property & Reference & year & $N_{P}$ & $T / \mathrm{K}$ & $P / \mathrm{MPa}$ & Uncertainty \\
\hline \multirow{7}{*}{ R1233zd(E) } & \multirow{2}{*}{$P^{s a t}$} & Nicola et al. ${ }^{2}$ & 2017 & 81 & $234.15-375.15$ & $0.007-1.09$ & $1 \mathrm{KPa}$ \\
\hline & & Mondejar et al. ${ }^{3}$ & 2015 & 23 & $280-437.9$ & $0.06-3.52$ & $1.97 \%$ \\
\hline & \multirow{3}{*}{$\rho$} & Fedele et al. ${ }^{14}$ & 2018 & 94 & $283.15-363.15$ & $0.13-35$ & $0.8 \%$ \\
\hline & & Romeo et al. ${ }^{24}$ & 2017 & 30 & $274.15-333.15$ & $1-25$ & $0.07 \%$ \\
\hline & & Mondejar et al. ${ }^{3}$ & 2015 & 41 & $275-365$ & $1-20$ & $0.22 \%$ \\
\hline & $C_{P}$ & Liu et al. ${ }^{25}$ & 2018 & 63 & $313.3-445.8$ & $1-10$ & $1.2 \%$ \\
\hline & $u^{g a s}$ & Mondejar et al. ${ }^{3}$ & 2015 & 155 & $290-419.5$ & $0.08-2.07$ & $0.026 \%$ \\
\hline
\end{tabular}




\begin{tabular}{|c|c|c|c|c|c|c|c|}
\hline \multirow{11}{*}{ R1234yf } & \multirow{2}{*}{$P^{\text {sat }}$} & Fedele et al. ${ }^{26}$ & 2011 & 40 & $245-343$ & $0.11-2.04$ & $1 \mathrm{KPa}$ \\
\hline & & Richter et al. ${ }^{27}$ & 2011 & 216 & $250-366$ & $0.13-3.1$ & $0.55 \mathrm{KPa}$ \\
\hline & \multirow{4}{*}{$\rho$} & Klomfar et al. ${ }^{28}$ & 2012 & 83 & $217-353$ & $0.9-40$ & $0.1 \%$ \\
\hline & & Fedele et al. ${ }^{29}$ & 2011 & 101 & 283.15-333.15 & $0.6-35$ & $0.08 \%$ \\
\hline & & Markus et al. ${ }^{27}$ & 2011 & 557 & $232-400$ & $0.55-9.6$ & $1.20 \%$ \\
\hline & & Qiu et al. ${ }^{4}$ & 2013 & 128 & $283-363$ & $1-100$ & $0.33 \%$ \\
\hline & \multirow{3}{*}{$C_{P}$} & Liu et al. ${ }^{5}$ & 2017 & 154 & $303-373$ & $1.5-12$ & $1 \%$ \\
\hline & & Gao et al. ${ }^{6}$ & 2014 & 74 & 305.15-355.15 & $1.5-5.08$ & $1.7 \%$ \\
\hline & & Tanaka et al. ${ }^{7}$ & 2010 & 22 & $310-360$ & $2.0-5.0$ & $5 \%$ \\
\hline & $u^{g a s}$ & Kano et al. ${ }^{8}$ & 2010 & 41 & 278.15-353.15 & $0.025-0.40$ & $0.01 \%$ \\
\hline & $u^{\text {liquid }}$ & Lago et al. ${ }^{30}$ & 2011 & 22 & $260-360$ & $2-6.06$ & $0.1 \%$ \\
\hline \multirow{11}{*}{ R1234ze(E) } & \multirow{4}{*}{$P^{\text {sat }}$} & Yin et al. ${ }^{10}$ & 2018 & 15 & $303-373$ & $0.57-3.02$ & $0.5 \mathrm{KPa}$ \\
\hline & & Gong et al. ${ }^{11}$ & 2016 & 10 & 253.3-293.3 & $0.09-0.42$ & $1 \mathrm{KPa}$ \\
\hline & & Nicola et al. ${ }^{12}$ & 2012 & 49 & 257.15-343.15 & $0.115-1.613$ & $1 \mathrm{KPa}$ \\
\hline & & Tanaka et al. $^{7}$ & 2010 & 8 & $310-380$ & $0.7-3.4$ & $1 \mathrm{KPa}$ \\
\hline & \multirow{2}{*}{$\rho$} & Gong et al. ${ }^{11}$ & 2016 & 10 & $253.3-293.3$ & $0.09-0.42$ & $0.01 \%$ \\
\hline & & Qiu et al. $^{4}$ & 2013 & 131 & $283.5-363$ & $1-100$ & $0.23 \%$ \\
\hline & \multirow{3}{*}{$C_{P}$} & Gao et al. ${ }^{13}$ & 2015 & 95 & $310.15-365.15$ & $1.56-5.49$ & $1.1 \%$ \\
\hline & & Tanaka et al. ${ }^{7}$ & 2010 & 26 & $310-370$ & $2-5$ & $5 \%$ \\
\hline & & Liu et al. ${ }^{21}$ & 2018 & 130 & 313.5-393.7 & $1-10$ & $1.11 \%$ \\
\hline & $u^{g a s}$ & Perkins et al. ${ }^{22}$ & 2015 & 223 & $280-420$ & $0.08-2.8$ & $0.041 \%$ \\
\hline & $u^{\text {liquid }}$ & Lago et al. ${ }^{9}$ & 2011 & 34 & $260-360$ & $2-10$ & $0.1 \%$ \\
\hline \multirow[t]{4}{*}{ R1234ze(Z) } & $P^{s a t}$ & Fedele et al. ${ }^{15}$ & 2014 & 28 & $238.13-372.6$ & $0.012-1.336$ & $1 \mathrm{KPa}$ \\
\hline & \multirow[b]{2}{*}{$\rho$} & Romeo et al. ${ }^{24}$ & 2017 & 36 & 273.15-333.15 & $1-30$ & $0.07 \%$ \\
\hline & & Fedele et al. ${ }^{15}$ & 2014 & 313 & 283.15-363.15 & $0.18-34$ & $0.07 \%$ \\
\hline & $u^{\text {liquid }}$ & Lago et al. ${ }^{16}$ & 2016 & 38 & 273.15-333.15 & $0.19-25$ & $0.05 \%$ \\
\hline \multirow{4}{*}{ R1243zf } & \multirow{2}{*}{$P^{\text {sat }}$} & Higashi et al. ${ }^{23}$ & 2018 & 20 & $310-376$ & $0.8-3.5$ & $1 \mathrm{KPa}$ \\
\hline & & Brown et al. ${ }^{17}$ & 2013 & 28 & $233.8-372.8$ & $0.053-3.255$ & $1 \mathrm{KPa}$ \\
\hline & $\rho$ & Nicola et al. ${ }^{18}$ & 2013 & 300 & $283.15-353.15$ & $1.3-34.5$ & $0.07 \%$ \\
\hline & $P^{\text {sat }}$ & Fedele et al. ${ }^{19}$ & 2016 & 42 & $255.15-345.15$ & 0.108-1.719 & $1 \mathrm{KPa}$ \\
\hline R1225ye(Z) & $\rho$ & Brown et al. ${ }^{27}$ & 2015 & 136 & 283.15-353.15 & $0.5-35$ & $0.07 \%$ \\
\hline
\end{tabular}

${ }^{*} N_{P}$ is the number of experimental data point. The reported uncertainty of experimental data is also shown. The highest uncertainties of data are from isobaric heat capacity. 
Thermodynamic modeling, when a reliable model is available, is a useful alternative to the traditional time-consuming and expensive experimental measurements. Thermodynamic models are very much needed in process design, simulation and optimization and they are indispensable for energy performance evaluation for refrigerants containing systems and processes. Both Equations of State (EoS) and molecular simulation techniques have been used for the HFO containing systems. Raabe et al. ${ }^{31-34}$ have studied the thermodynamic properties of selected HFO refrigerants and their mixtures with carbon dioxide as well as HFCs in a systematic way by molecular simulations as well as using the PC-SAFT model. Lai et al. ${ }^{35-38}$ used the BACKBONE EoS for predicting properties of pure HFOs refrigerants, while Fouad and Vega ${ }^{39}$ applied the Polar Perturbed-Chain SAFT (PC-SAFT) EoS for phase and interfacial properties of mixtures containing HFOs, also as a means for studying the multipolar interactions. However, in most of these studies the methods of parameter estimation were not explicitly discussed and it is, thus, not clear which are the best estimation methods and which properties should be used in the model development for this type of novel refrigerants.

In this work, the PC-SAFT ${ }^{40,41}$ and Cubic Plus Association (CPA) ${ }^{42}$ EoS are used not just for comparison and validation purposes for HFOs but also with the purpose of carrying out an indepth analysis the impact of the parameter estimation method on model development and validation.

\section{Models, Properties and Parameter Estimation}

The two models used in this work, CPA and PC-SAFT, are briefly introduced here. The CPA EoS proposed by Kontogeorgis et al. ${ }^{42}$ combines the Soave-Redlich-Kwong (SRK) ${ }^{43}$ equation, widely used in the petroleum industry, with an association term, which is similar to that used in SAFT $^{44-46}$. CPA reduces to SRK for non-associating compounds. This guarantees that the CPA 
model maintains the advantages of the simplicity of cubic EoS for many compounds, e.g those of relevance to the oil and gas industry. Besides that, the numerical implementation of the association term ensures that the computation time is not much higher than that of SRK and other simple classical models. The expression for CPA is as follows:

$$
P=\frac{R T}{V_{m}-b}-\frac{a(T)}{V_{m}\left(V_{m}+b\right)}-\frac{1}{2} \frac{R T}{V_{m}}\left(1+\rho \frac{\partial \ln g}{\partial \rho}\right) \sum_{i} x_{i} \sum_{A_{i}}\left(1-X_{A_{i}}\right)
$$

where $\rho$ is the molar density $\left(\rho=1 / V_{m}\right)$. The detailed description of CPA can be found in the book by Kontogeorgis and Folas ${ }^{47}$. In many cases in this work the association term is zero and thus CPA reduces to the SRK functionality but with parameters fitted to various properties, and not just vapor pressures and critical point, the latter method being typically the case with cubic EoS.

The PC-SAFT model is a widespread theoretical-based EoS, which was proposed by Gross and Sadowski ${ }^{40}$. This model, besides considering hard-chain reference in the perturbation term, it uses the same chain term and association term as the original SAFT ${ }^{44-46}$. In the PC-SAFT equation, the general expression of the residual Helmholtz energy is shown below:

$$
A^{r e s}=A^{h c}+A^{d i s p}+A^{a s s}
$$

In this work, we focus on the representation of both the ordinary widely used thermodynamic properties like vapor pressures and the much more demanding derivative properties. According to Gregorowicz et al..$^{48}$, many EoS are able to predict with good accuracy the first-order derivatives, but the precise description of the second-order derivative properties is still challenging, especially for classical EoS, like $\mathrm{PR}^{49}$. This may be due to inherent limitations of these cubic EoS or due to the parameter estimation. Recently, much interest has been given on molecular SAFT-type EoS application for derivative properties, sometimes with rather mixed results ${ }^{39,50,51}$.

The second-order derivative properties considered here are given by the following equations: 


$$
\begin{gathered}
C_{P}^{r e s}=-n R-T\left(\frac{\partial^{2} A^{r}}{\partial T^{2}}\right)_{V, n}+R T\left(\frac{\partial P}{\partial T}\right)_{V, n}\left(\frac{\partial V}{\partial T}\right)_{P, n} \\
C_{P}=n\left(C_{P}^{i g}-R\right)-T\left(\frac{\partial^{2} A^{r}}{\partial T^{2}}\right)_{V, n}+R T\left(\frac{\partial P}{\partial T}\right)_{V, n}\left(\frac{\partial V}{\partial T}\right)_{P, n} \\
u=\sqrt{-\frac{V^{2}}{M_{W}} \frac{C_{P}}{C_{V}}\left(\frac{\partial P}{\partial V}\right)_{T, n}} \\
\kappa_{T}=\left(\frac{1}{\rho}\right)\left(\frac{\partial \rho}{\partial P}\right)_{T} \\
\alpha_{P}=-\left(\frac{1}{\rho}\right)\left(\frac{\partial \rho}{\partial T}\right)_{P}
\end{gathered}
$$

As seen from these equations, an accurate description of these derivative properties requires an accurate representation of density or volume $(V)$, and the derivative of pressure with respect to volume $(\partial P / \partial V)$ and the derivative of pressure with respect to temperature $(\partial P / \partial T)$. Detailed explanation of how to get these derivatives analytically from an EoS can be found in Chapter 2 of the book by Michelsen and Mollerup ${ }^{52}$.

We have applied CPA and PC-SAFT in correlating and predicting the thermodynamic properties of pure HFOs refrigerants. First, the model parameters should be estimated from experimental data of pure compounds. Most often, vapor pressures and saturated liquid densities over extensive temperature range are used (classical method). However, better results may be obtained with other estimation methods and indeed the target of this work is to evaluate various parameter estimation methods. In total, eleven (11) estimation methods summarized in Table 2, have been considered using different types of properties for obtaining the model parameters. The properties considered in various combinations are vapor pressure, saturated liquid density, liquid density under low pressure, all liquid density available in literature, speed of sound in liquid phase and isobaric heat capacity. 
Table 2. Properties used in the parameter estimation

\begin{tabular}{ccccccc}
\hline & $P^{\text {sat }}$ & $\rho^{\text {sat }}$ & $\rho^{\text {low pressure }}$ & $\rho^{\text {all }}$ & $u^{\text {liquid }}$ & $C_{P}$ \\
\hline method 1 & $\sqrt{ }$ & $\sqrt{ }$ & & & & \\
\hline method 2 & $\sqrt{ }$ & $\sqrt{ }$ & & & & \\
\hline method 3 & $\sqrt{ }$ & & $\sqrt{ }$ & & & \\
\hline method 4 & $\sqrt{ }$ & & & $\sqrt{ }$ & & \\
\hline method 5 & & $\sqrt{ }$ & & & & \\
\hline method 6 & & & & $\sqrt{ }$ & & \\
\hline method 7 & $\sqrt{ }$ & $\sqrt{ }$ & & & & $\sqrt{ }$ \\
\hline method 8 & $\sqrt{ }$ & & $\sqrt{ }$ & & & \\
\hline method 9 & $\sqrt{ }$ & $\sqrt{ }$ & & & $\sqrt{ }$ & \\
\hline method 10 & $\sqrt{ }$ & & $\sqrt{ }$ & & $\sqrt{ }$ & \\
\hline method 11 & $\sqrt{ }$ & & & $\sqrt{ }$ & $\sqrt{ }$ & $\sqrt{ }$ \\
\hline
\end{tabular}

${ }^{*}$ Method 2 is the same as method 1 , except that the molecules are assumed to be self-associating using the two-site (2B) association scheme.

The parameters of PC-SAFT and CPA were determined by minimizing the following objective function (OF):

$$
\begin{gathered}
O F=\sum_{i}^{N} w_{X} * \sum_{j}^{N_{p}}\left[\left(\frac{X_{j}^{\text {cal }}-X_{j}^{\text {exp }}}{X_{j}^{\text {exp }}}\right)^{2}\right] \\
X=P^{\text {sat }}, \rho^{\text {sat }}, \rho^{\text {low pressure }}, \rho^{\text {all }}, u^{\text {liquid }}, C_{P}
\end{gathered}
$$

Where $w_{X}, N, N_{p}, P^{\text {sat }}, \rho^{\text {sat }}, \rho^{\text {low pressure }}, \rho^{\text {all }}$, $u^{\text {liquid }}$ and $C_{P}$ are weighting factors, number of properties used in parameter estimation, total experimental points, vapor pressure, saturated liquid densities, liquid densities under low pressure, all density data available, speed of sound in liquid phase and isobaric heat capacity, respectively. The values of $w_{X}$ and $N$ depend on which method is chosen, as shown in Table 2. The experimental data used are summarized in Table 1. 
In this work, the percentage average absolute deviation $(\% A A D)$ is defined as

$$
\% A A D(X)=\frac{1}{N_{p}} \sum_{j}^{N_{p}}\left|\frac{X_{j}^{c a l}-X_{j}^{\text {exp }}}{X_{j}^{\text {exp }}}\right| \times 100 \%
$$

\section{Results}

The obtained pure component parameters with both models and all methods are presented in the Tables S1 and S2 in the Support Information. The \%AAD between experimental data and calculated values for the various thermodynamic properties using different methods are presented in Tables 3 and 4 for CPA and PC-SAFT, respectively. As mentioned above, the experimental data of R1234zf and R1225ye(Z) are not considered in the parameter estimation and the \%AAD results shown in Tables 3 and 4 . Isothermal Compressibility $\kappa_{T}$ and isobaric thermal expansivity $\alpha_{P}$ are introduced to evaluate the predictive capability of the models.

Table 3. $\% A A D$ of thermodynamic properties from CPA with different methods

\begin{tabular}{llllllllllll}
\hline & $P^{\text {sat }}$ & $\rho^{\text {sat }}$ & $\rho^{l p}$ & $\rho^{\text {all }}$ & $C_{P}$ & $C_{P}^{\text {res }}$ & $u^{\text {gas }}$ & $u^{\text {liquid }}$ & $\kappa_{T}$ & $\alpha_{P}$ & $A A D^{a l *^{*}}$ \\
\hline method 1 & 0.25 & 0.67 & 1.39 & 1.60 & 3.10 & 8.97 & 0.87 & 16.8 & 24.2 & 8.68 & 4.01 \\
\hline method 2 & 0.13 & 0.43 & 0.76 & 1.73 & 2.65 & 7.78 & 1.03 & 15.7 & 19.6 & 9.37 & 3.61 \\
\hline method 3 & 0.24 & 0.79 & 0.82 & 1.60 & 2.44 & 7.17 & 0.78 & 17.5 & 25.8 & 8.63 & 4.03 \\
\hline method 4 & 0.28 & 2.50 & 2.55 & 1.00 & 3.80 & 10.8 & 0.70 & 17.3 & 28.1 & 9.24 & 4.60 \\
\hline method 5 & 79.2 & 0.16 & 0.56 & 2.35 & 8.82 & 25.3 & 0.59 & 22.1 & 39.7 & 11.0 & 17.9 \\
\hline method 6 & 41.5 & 0.96 & 0.50 & 0.30 & 18.9 & 54.7 & 0.68 & 2.95 & 7.62 & 7.87 & 10.7 \\
\hline method 7 & 1.60 & 0.45 & 1.26 & 1.83 & 1.62 & 4.59 & 0.80 & 16.7 & 23.3 & 8.19 & 3.87 \\
\hline method 8 & 1.48 & 0.91 & 0.67 & 2.10 & 1.63 & 4.63 & 0.56 & 16.7 & 22.9 & 8.65 & 3.96 \\
\hline method 9 & 0.25 & 0.67 & 1.42 & 1.80 & 3.09 & 8.92 & 0.87 & 16.8 & 24.1 & 8.67 & 4.05 \\
\hline method 10 & 0.24 & 1.79 & 0.93 & 1.08 & 3.52 & 10.1 & 0.79 & 17.1 & 26.9 & 9.08 & 4.34 \\
\hline method 11 & 1.20 & 2.27 & 2.17 & 0.95 & 1.93 & 5.61 & 0.59 & 17.11 & 26.55 & 8.49 & 4.17 \\
\hline
\end{tabular}

\footnotetext{
${ }^{*} A A D^{\text {all }}$ is the value of $\% A A D$ containing all thermodynamic properties except $C_{P}^{r e s}$ for HFOs considered.
} 
Table 4. \%AAD of thermodynamic properties from PC-SAFT with different methods.

\begin{tabular}{cccccccccccc}
\hline & $P^{\text {sat }}$ & $\rho^{\text {sat }}$ & $\rho^{\text {lp }}$ & $\rho^{\text {all }}$ & $C_{P}$ & $C_{P}^{\text {res }}$ & $u^{\text {gas }}$ & $u^{\text {liquid }}$ & $\kappa_{T}$ & $\alpha_{P}$ & $A A D^{\text {all }}$ \\
\hline method 1 & 0.06 & 0.39 & 0.38 & 0.81 & 3.74 & 10.9 & 0.37 & 4.64 & 9.12 & 4.28 & 2.05 \\
\hline method 2 & 0.26 & 0.09 & 0.28 & 1.37 & 2.60 & 7.64 & 0.56 & 10.9 & 17.8 & 2.67 & 2.67 \\
\hline method 3 & 0.12 & 0.33 & 0.28 & 0.81 & 3.75 & 11.0 & 0.37 & 4.60 & 8.91 & 4.17 & 2.02 \\
\hline method 4 & 0.21 & 0.65 & 0.67 & 0.53 & 3.84 & 11.2 & 0.37 & 4.59 & 9.49 & 4.20 & 2.08 \\
\hline method 5 & 30.8 & 0.03 & 0.34 & 1.17 & 12.4 & 36.3 & 0.66 & 10.9 & 8.70 & 5.44 & 8.21 \\
\hline method 6 & 29.0 & 0.44 & 0.34 & 0.17 & 6.81 & 20.1 & 1.16 & 5.94 & 6.97 & 3.01 & 6.46 \\
\hline method 7 & 1.23 & 0.73 & 0.49 & 0.98 & 2.01 & 5.73 & 0.39 & 5.15 & 8.83 & 6.23 & 2.19 \\
\hline method 8 & 1.71 & 0.84 & 0.55 & 0.71 & 1.82 & 5.21 & 0.42 & 5.13 & 8.56 & 7.48 & 2.22 \\
\hline method 9 & 0.13 & 0.45 & 0.30 & 0.94 & 3.80 & 11.1 & 0.37 & 4.59 & 8.92 & 4.11 & 2.08 \\
\hline method 10 & 0.12 & 0.59 & 0.44 & 0.82 & 3.86 & 11.2 & 0.38 & 4.59 & 9.28 & 4.07 & 2.10 \\
\hline method 11 & 0.81 & 0.68 & 0.58 & 0.50 & 2.46 & 7.33 & 0.48 & 4.93 & 9.32 & 4.76 & 1.98 \\
\hline
\end{tabular}

${ }^{*} A A D^{\text {all }}$ is the value of \%AAD containing all thermodynamic properties except $C_{P}^{\text {res }}$ for HFOs
considered.

\subsection{Methods of parameter estimation}

To better compare these methods, we categorize them into five groups based on the experimental data type involved in the process of fitting, described as follows:

(i) Vapor pressure + liquid density

(ii) Liquid density only

(iii) Vapor pressure + liquid density + isobaric heat capacity

(iv) Vapor pressure + liquid density + speed of sound in liquid phase

(v) Vapor pressure + liquid density + isobaric heat capacity + speed of sound in liquid phase

In the following subsections, the above-mentioned five (5) groups of methods will be presented and discussed. 


\section{(i) Vapor pressure + liquid density}

Four methods (methods 1-4) are compared, all of which consider vapor pressure and liquid density in the parameter estimation. As the most popular and classical method of fitting, the first method, namely using solely vapor pressure and saturated liquid density (from NIST database ${ }^{53}$ ), is considered first. The databas $\mathrm{e}^{53}$ uses sophisticated Helmholtz-based EoS with many parameters ${ }^{27,54-56}$ to determine the different properties with reference experimental data. This method can be considered as the benchmark for all the other methods and can help in the final recommendation. Unfortunately, although experimental vapor pressure data are relatively easy to obtain from literature, experimental saturated liquid density for such novel refrigerants are scarce. In order to put forward some more reasonable and feasible methods, we replace saturated densities with liquid densities under low pressure (in method 3) and all literature liquid densities (method 4). Besides, since method 4 introduces more liquid density data into the parameter estimation, it might provide a better overall description of density. Thus, a better estimation of pressure-volume $\partial P / \partial V$ derivatives and second-order derivative thermodynamic properties involving $\partial P / \partial V$ term is obtained, which is usually hard to achieve accurately, especially in the compressed liquid phase. Some refrigerant molecules are polar and such interactions can be, rather empirically, modelled as associating. Thus, we have also used method 2 with a two-site (2B) association scheme. This is in analogy to the extensive study of refrigerants using the SAFT method by Swaminathan and Visco $^{50,51}$. They developed the SAFT-VR model with a two-site association scheme for 49 pure refrigerants that have non-zero dipole moment, irrespective of their molecular structure. Furthermore, the objective of this method is to investigate whether introducing the association term could help developing a reliable model for describing the thermodynamic properties for HFOs over a wide range of conditions. The results are shown in Tables 3 and 4 . 
Considering that the difference between the results obtained with methods 1-4 is quite small, only calculations with method 3 are presented graphically here. Figure 2 shows $C_{P}$ predictions for R1234yf and R1234zd(E) at selected temperatures and pressures with CPA and PC-SAFT. The ideal gas isobaric heat capacity is obtained from the NIST database ${ }^{53}$. Both models overestimate $C_{P}$ at all temperatures and pressures studied, especially at evaluated pressures. The performance improves as the pressure decreases for both models. CPA provides superior $C_{P}$ predictions compared to PC-SAFT. Looking at Equation (4), the results indicate a wrong estimation of $\partial P / \partial T$ and $\partial V / \partial T$. Simultaneously, the deviation of these two terms to some extent might cancel out when applying CPA.
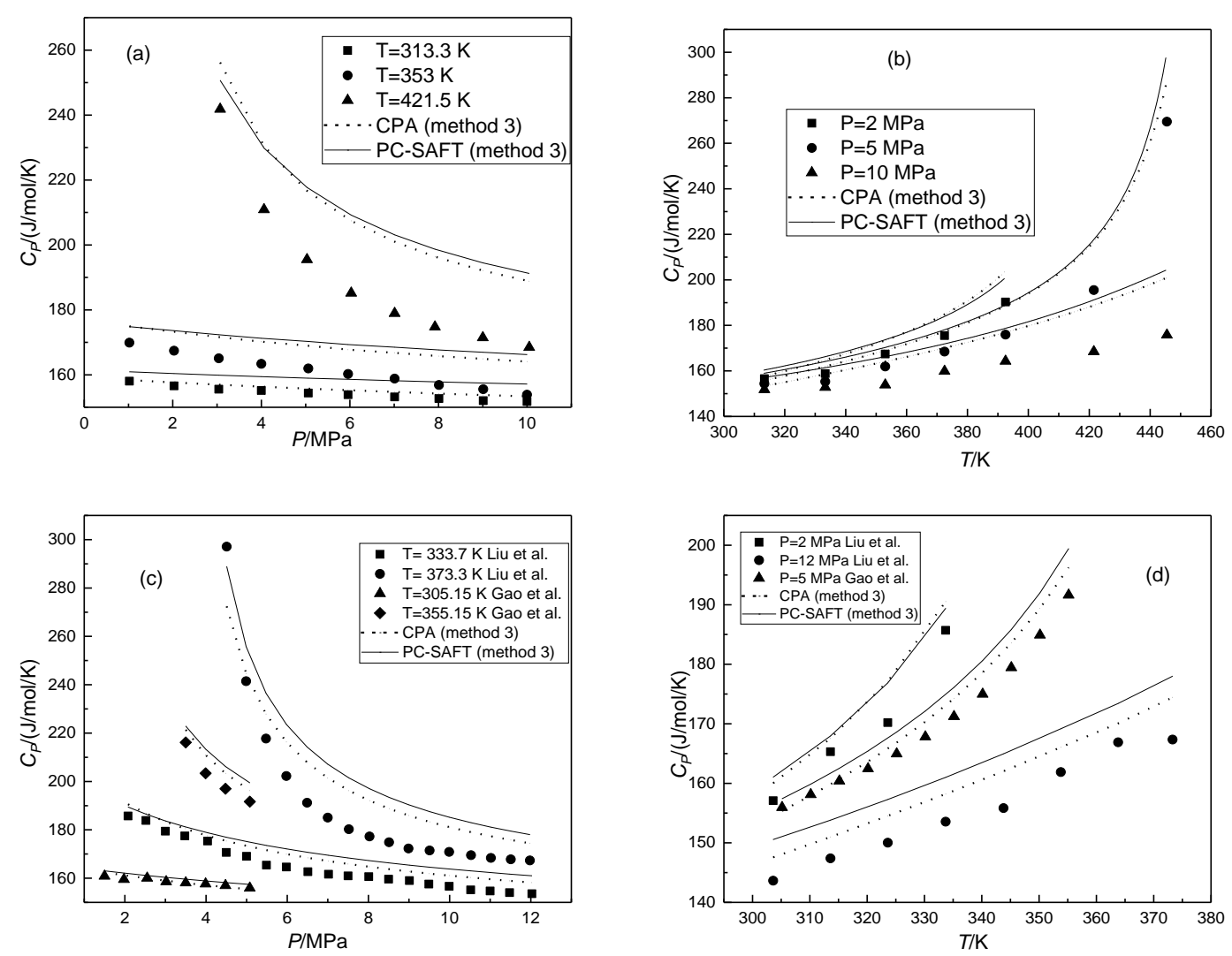

Figure 2. Isobaric heat capacity predictions of R1233zd(E) and R1234yf as functions of temperature and pressure with CPA and PC-SAFT. The data of R1233zd(E) (a, b) are from Liu et al. ${ }^{25}$ and the data of R1234yf (c, d) are from Liu et al. ${ }^{5}$ and Gao et al. ${ }^{6}$ 
To illustrate the observed trends better, calculation results of $C_{P}^{\text {res }}$ (residual isobaric heat capacity given in Equation (3)) with method 3 for R1234yf and R1233zd(E) are presented in Figure 3.

As seen from Figures 2 and 3, the plots of $C_{P}$ and $C_{P}^{r e s}$ show similar trends. CPA provides satisfactory $C_{P}$ predictions of R1234yf with \%AAD value below $3 \%$ for the temperatures and pressures considered but fails for R1233zd(E). However, since the uncertainty of literature data is relatively large, the results in the low-medium pressure region (less than $5 \mathrm{MPa}$ ) may still be considered to be acceptable.
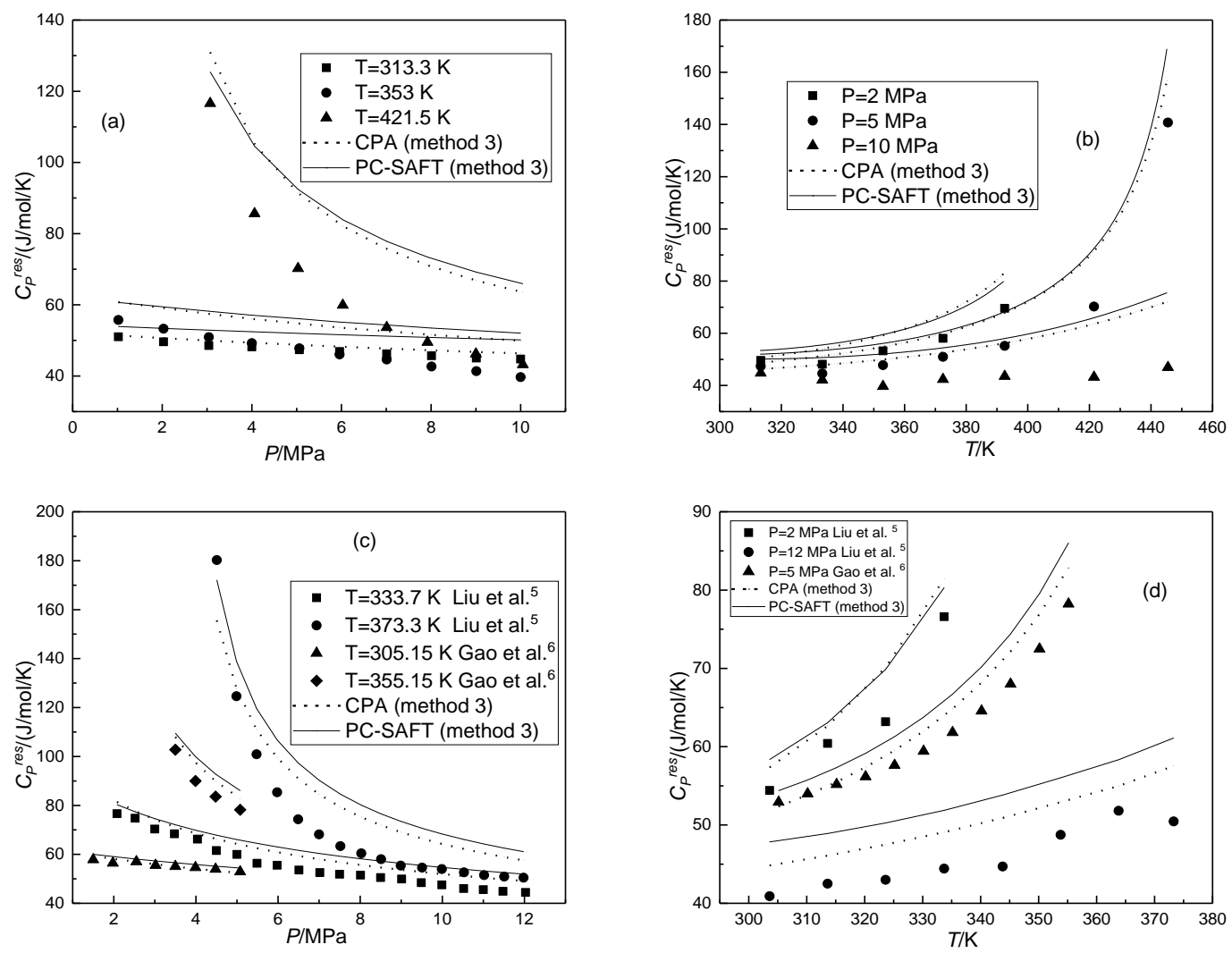

Figure 3. Residual isobaric heat capacity predictions of R1233zd(E) (a, b) and R1234yf (c, d) as functions of temperature and pressure with CPA and PC-SAFT, compared with calculations from experimental $C_{P}$ data ${ }^{5,6,25}$ and $C_{P}^{i g}$ from NIST database ${ }^{53}$. 
The comparisons between experimental speed of sound in liquid phase and calculations with methods 2 and 3 of R1234yf are shown in Figure 4. It is seen (from Tables 3, 4 and Figure 4) that introducing the association term improves the performance of heat capacity for both models, while a deterioration of other properties is also seen, like $u$ and $\kappa_{T}$ with PC-SAFT and $\alpha_{P}$ with CPA.

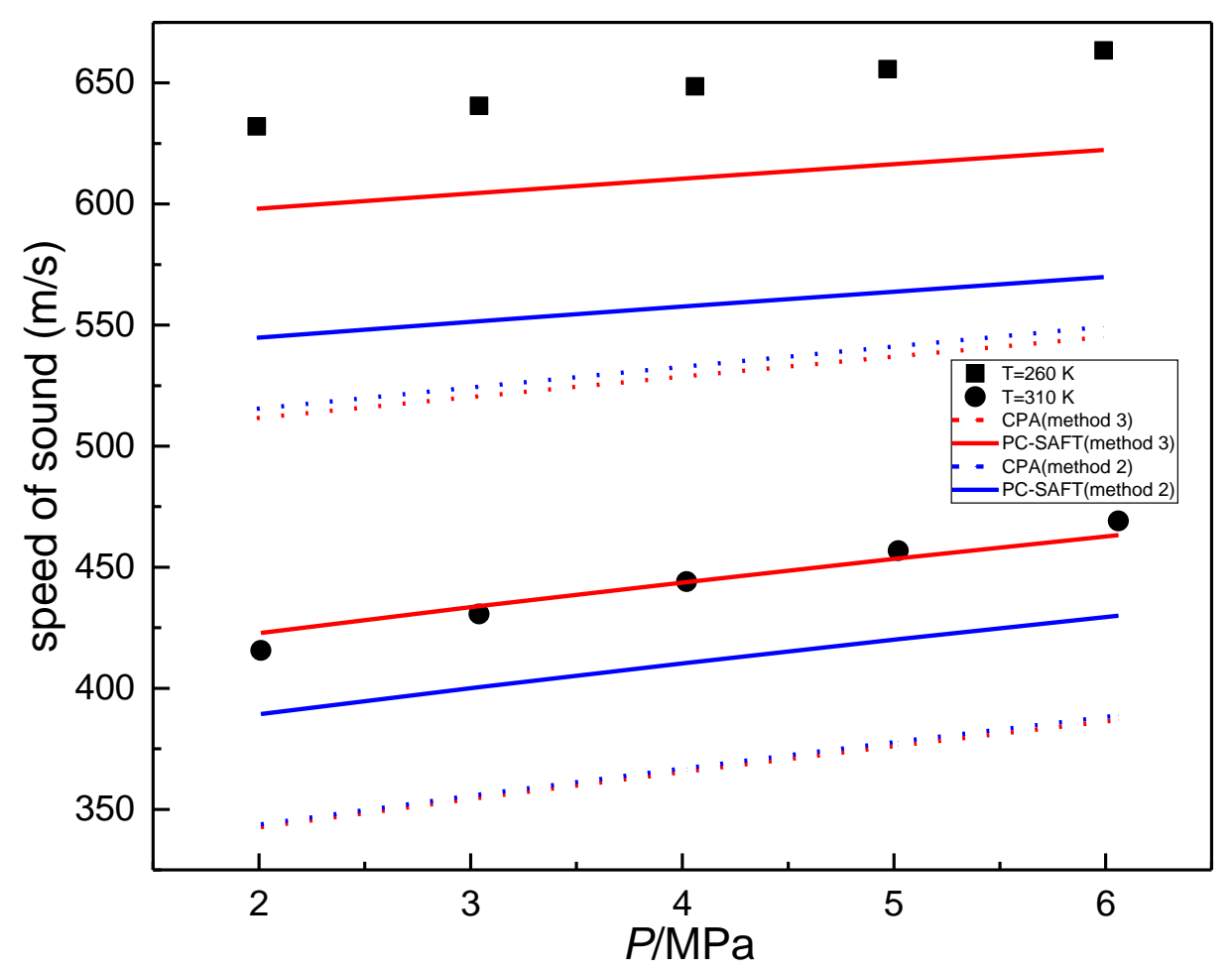

Figure 4. Speed of sound in R1234yf at $T=260 \mathrm{~K}$ and $310 \mathrm{~K}$. Symbols are data from Lago et al. ${ }^{9}$, and dotted and solid lines are results from CPA and PC-SAFT with methods 2 and 3, respectively.

\section{(ii) Liquid density only}

We have then investigated methods 5 and 6, where only liquid densities were used in the parameter estimation process. It is expected that such a method may yield the optimum description of pressure-volume $(\partial P / \partial V)$ and pressure-temperature $(\partial P / \partial T)$ derivatives, thus improving the calculations of second-order derivative properties which contain these two terms for HFOs. 
The results with method 6 do show that it can describe the properties containing the $\partial P / \partial V$ and $\partial P / \partial T$ terms better, especially with CPA. For instance, method 6 with CPA does a good job in describing the speed of sound, giving better $u$ predictions ( $\% A A D=3 \%$ ) compared to all other methods. However, not introducing vapor pressure into the parameter estimation is very problematic. As can be seen in Figure 5, for method 6, we get very poor results for vapor pressures with both CPA and PC-SAFT.

In Figure 6, the experimental and calculated speed of sound of R1234yf using method 6 is presented. It can be seen that, using method 6, the capability to predict speed of sound is improved over the other methods, especially for CPA.

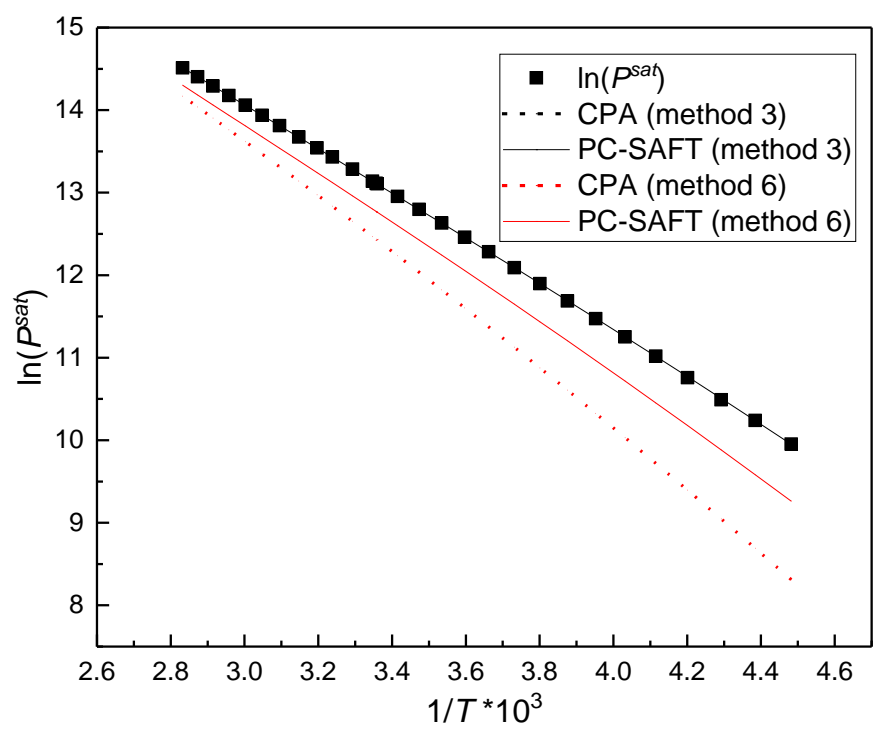

Figure 5. Vapor pressure for R1234ze(E) with CPA (dotted lines) and PC-SAFT (solid lines) using methods 3 (black) and 6 (red). Symbols are published data from literature ${ }^{12}$. 


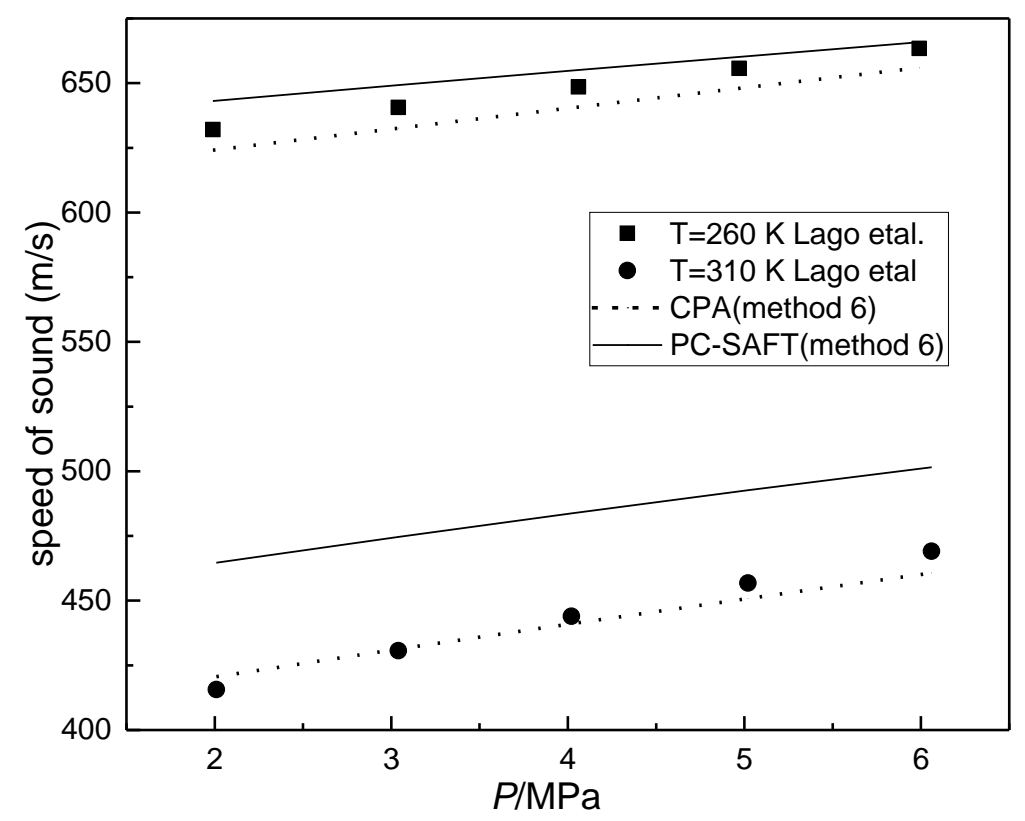

Figure 6. Speed of sound in R1234yf at $T=260 \mathrm{~K}$ and $310 \mathrm{~K}$. Symbols are data from Lago et al. ${ }^{9}$. and dotted and solid lines are results of CPA and PC-SAFT with method 6, respectively.

\section{(iii) Vapor pressure + liquid density + isobaric heat capacity}

Two parameter estimation methods have been proposed to improve the accuracies of CPA and PC-SAFT for derivative properties: (1) using $C_{P}$, vapor pressure and saturated liquid densities (method 7); (2) using $C_{P}$,vapor pressure and liquid densities under low pressure (method 8).

It can be seen from Tables 3 and 4 that both of these methods give good results of $C_{P}$, with percentage deviation around 2\%. A typical example is shown in Figure 7 for R1233zd(E) where the results are within experimental uncertainty. Furthermore, the performance in predicting vapor pressure is worse (compared to the classical method), with percentage deviation about $1.7 \%$ with both models, close to the experimental uncertainty for this property according to literature (approximately 2\%). The calculated values of other thermodynamic properties exhibit no noticeable improvement and are sometimes worse compared to other methods, as shown in Tables 3 and 4 . 

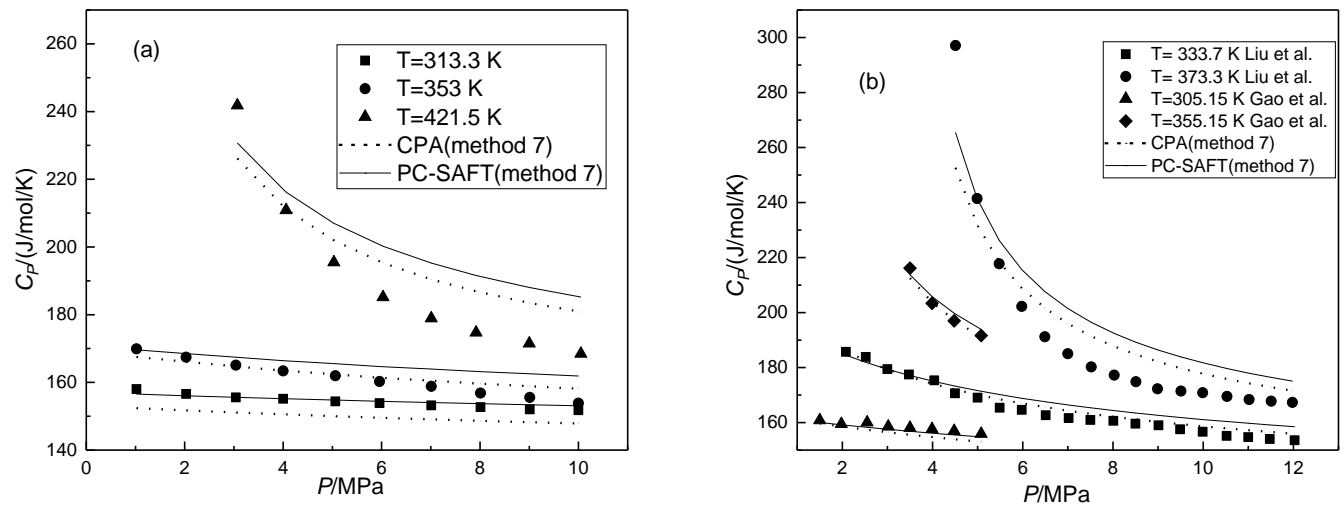

Figure 7. Comparison between isobaric heat capacity calculations of R1233zd(E) (a) and R1234yf (b) as a function of pressure with CPA and PC-SAFT. The experimental data are from Liu et al ${ }^{25}$.

\section{(iv) Vapor pressure + liquid density + speed of sound in liquid phase}

We have also investigated whether the performance of the models in predicting derivative properties can be improved by adding speed of sound data into the parameter estimation, methods 9 and 10, using either saturated liquid densities or liquid densities under low pressure. A typical calculation is shown in Figure 8, where it can be seen that there is little difference in the performance of these two estimation methods. Considering also the results in Tables 3 and 4, we conclude that including experimental speed of sound data into the parameter estimation process cannot yield a performance which is much better than the other methods for these compounds. Not surprisingly, PC-SAFT captures the curvature of speed of sound better than CPA. This may be due to PC-SAFT providing a more accurate description of derivative of pressure with respect to volume, which is the dominant term in calculating speed of sound. 


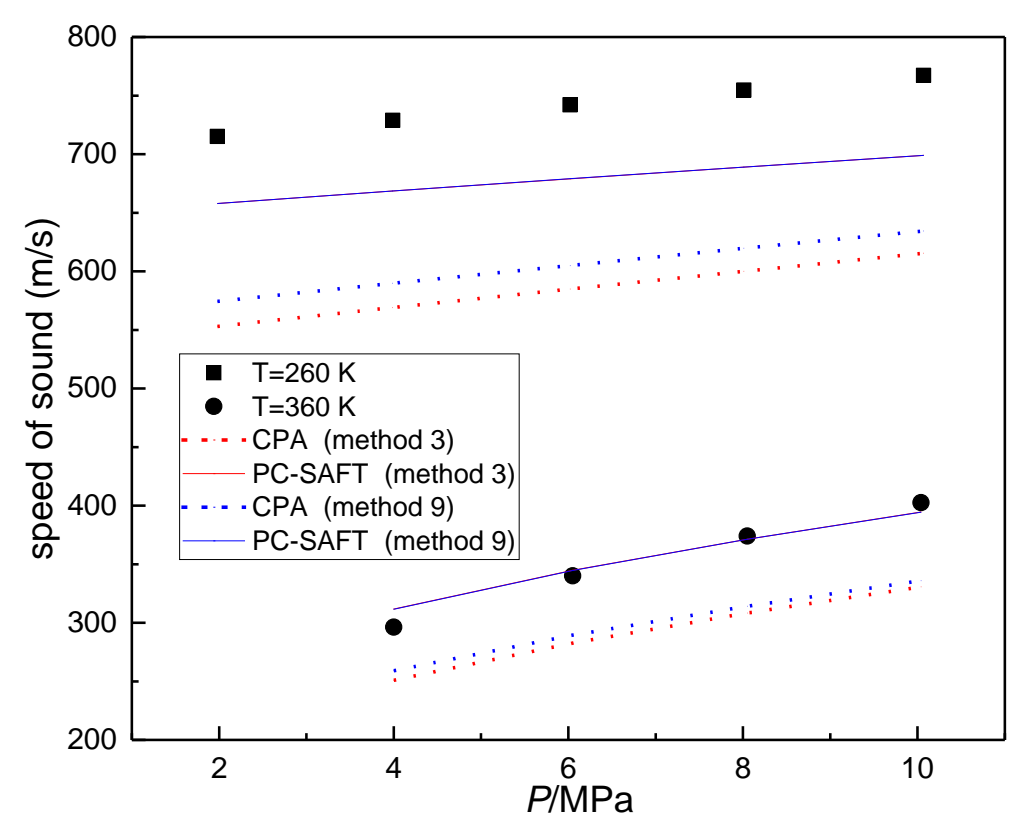

Figure 8. Speed of sound in R1234ze(E) at $T=260 \mathrm{~K}$ and $310 \mathrm{~K}$. Symbols are data from Lago et $\mathrm{al}^{30}$., and dotted and solid lines are results of CPA and PC-SAFT with methods 3 and 9, respectively.

\section{(v) Vapor pressure + liquid density + isobaric heat capacity + speed of sound in liquid phase}

In method 11, vapor pressure, all liquid density, isobaric heat capacity and speed of sound in liquid phase are considered in the parameter estimation. It can be seen from Tables 3 and 4 that using this method, a slight improvement of the isobaric heat capacity is obtained. However, besides relying on more experimental data and also having a heavier computational load, using this method the performance of both models on primary properties becomes worse, and this is the case for both saturated pressure and liquid density. Figure 9 presents a comparison of the calculated saturated liquid density and data from NIST database ${ }^{53}$. Detailed information on pure component parameters and deviations of method 11 is available in the Support Information and Tables 3 and 4. 


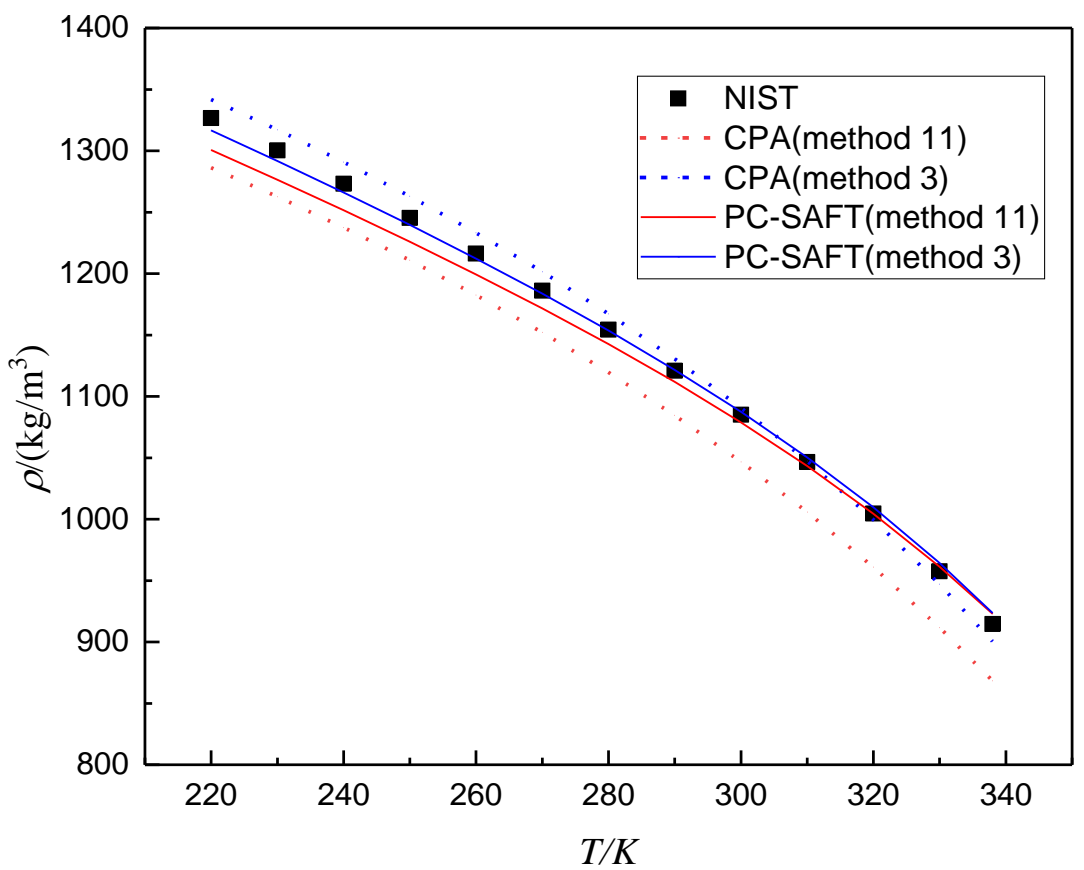

Figure 9. Saturated liquid density of R1234yf with CPA (dotted lines) and PC-SAFT (solid lines) using methods 3 (blue) and 11 (red). Symbols are data from NIST database ${ }^{53}$.

\subsection{Results for Isothermal Compressibility $\left(\kappa_{T}\right)$ and Isobaric Thermal Expansivity $\left(\alpha_{P}\right)$}

All isothermal compressibility and isobaric thermal expansivity data used to evaluate CPA and PC-SAFT are from the NIST database ${ }^{53}$ in the absence of actual experimental data. The percentage deviations shown in Tables 3 and 4 illustrate that the results are overall acceptable in most cases, except for the calculations with method 5 with CPA and method 2 with PC-SAFT. A comparison of the two models using method 3 for R1234yf is shown in Figure 10.

According to their definition, the isothermal compressibility and isobaric thermal expansivity can also be derived from the "analytical calculation" of correlations (Tait equation) or experimental data for the volumetric behavior against pressure and temperature, called "numerical method” in Figure 10. 

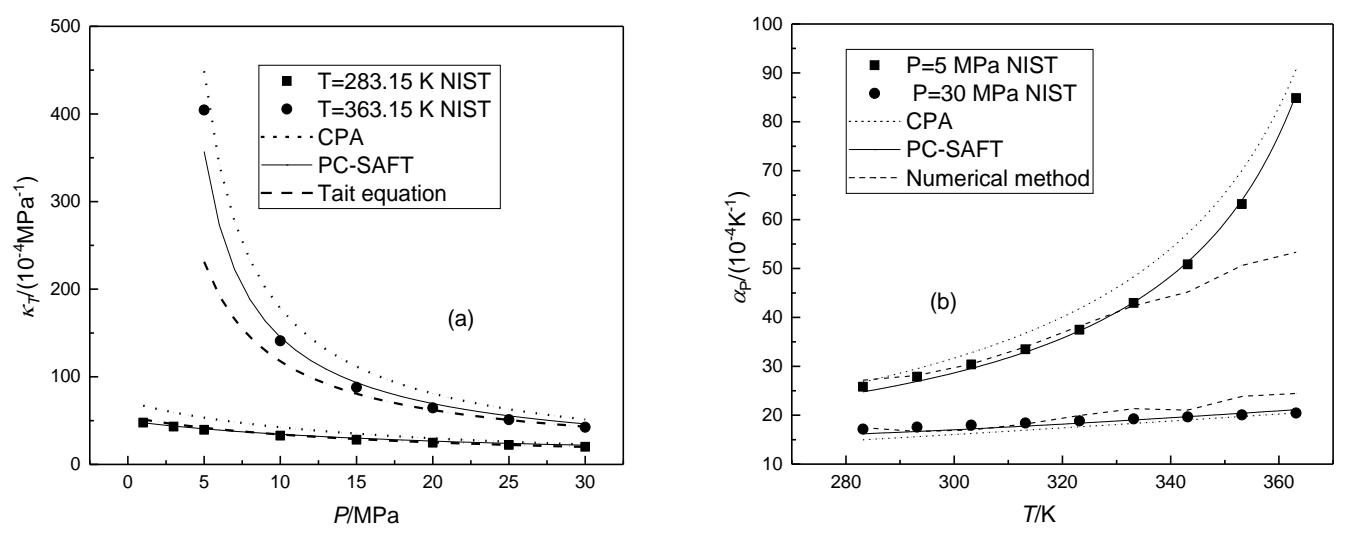

Figure 10. Isothermal compressibility (a) and isobaric thermal expansivity (b) as functions of temperature and pressure for R1234yf with CPA, PC-SAFT with method 3, Tait equation and a numerical method. Symbols are data from NIST database ${ }^{53}$.

The isothermal compressibility $\kappa_{T}$ is calculable by an analytical differentiation of the Tait equation ${ }^{57}$ with pressure:

$$
\kappa_{T}=\left(\frac{1}{\rho}\right)\left(\frac{\partial \rho}{\partial P}\right)_{T}=\frac{C}{\left(1-C \ln \left(\frac{B(T)+P}{B(T)+0.1}\right)\right)(B(T)+P)}
$$

Indeed, the modified Tait equation is an integrated form of an empirical equation of the isothermal compressibility behavior versus pressure. According to Rowlinson ${ }^{58}$, this way is certainly the most direct way to calculate reliable values for $\kappa_{T}$.

In a similar way, the isobaric thermal expansivity $\alpha_{P}$ can be obtained from an analytical calculation. However, the estimated $\alpha_{P}$ values depend highly on the applied temperaturedependent function $B(T)$, i.e. different analytical forms chosen for them may result in different temperature dependencies of $\alpha_{P}$. The numerical method using an incremental procedure avoids this problem. Cerdeirina ${ }^{59}$ stated that it is better to calculate the derivative by increments (i.e. by evaluating the density change corresponding to a temperature change). The key to calculating the derivatives is choosing an appropriate temperature change interval. For calculations to be conceptually correct, the density should vary in a linear manner over the temperature change. The 
width of this interval used in this work is $10 \mathrm{~K}$. Moreover, Troncoso ${ }^{60}$ evaluated this numerical method and found deviations systematically smaller than the estimated uncertainty in the investigated pressure and temperature ranges. Figure 10 shows the comparison between the aforementioned methods and advanced EoS with method 3 for R1234yf. At higher pressures, the results of numerical calculations of isothermal compressibility and isobaric thermal expansivity are quite similar with CPA and PC-SAFT. Nevertheless, at lower pressures, the calculations of isobaric heat expansivity with the numerical method deviate seriously from those with the other models at higher temperature. A non-smooth behavior for $\alpha_{P}$ is observed with the numerical method, which is because the numerical method relies on experimental data directly which also leads to high dependence on the accuracy of these data. It is not surprising that $\alpha_{P}$ can fluctuate slightly once there is some deviation between the published data, with whatever uncertainties they may have, and the true values.

\section{Discussion}

We start the discussion with the traditional method of parameter regression for SAFT variants, namely method 1 . This method yields results, which are neither the best nor the worst for any of the properties, but are acceptable for vapor pressure and liquid density $(0.3 \%$ and $0.8 \%$ deviations for the HFOs). For a second-order derivative property like isobaric heat capacity, CPA could give a 3\% error, which is also acceptable in view of the large measurement uncertainty. Still, using the classical method 1, neither CPA nor PC-SAFT could describe isothermal compressibility, speed of sound in liquid phase and isobaric thermal expansivity very satisfactorily.

To improve the description of the pressure-volume $(\partial P / \partial V)$ and pressure-temperature $(\partial P / \partial T)$ derivatives, we have considered methods 5-6. Using method 6, we have, indeed, improved the performance of the derivative properties containing $\partial P / \partial V$ and $\partial P / \partial T$. Method 6 with CPA 
provides the best description for speed of sound with less than 3\% deviation. Nevertheless, compared to the other methods, using only liquid density in the parameter estimation results in very poor vapor pressures. It is important that improvement of the second-order derivative properties is not achieved at the expense of significant deterioration of important primary properties (like vapor pressure and liquid density). Therefore, it can be concluded that parameter estimation using only liquid densities cannot provide acceptable results with CPA and PC-SAFT, at least for this type of compounds.

Then we focus on improving the models' capability to describe second-order derivative properties while maintaining a good performance for the primary properties. The solution we considered was to fit the model parameters with additional experimental data including also second-order derivative properties in the parameter estimation. Towards this direction, we have added speed of sound (method 9 and 10) and isobaric heat capacity data in compressed liquid phase (method 7 and 8) into the parameter estimation together with vapor pressure and liquid density data. Unfortunately, no significant improvements are seen in the derivative properties. In addition, an important method of implementing all available data (vapor pressure, liquid density, isobaric heat capacity and speed of sound in liquid phase), i.e. method 11, is also investigated. According to the results shown in Tables 3 and 4, this method cannot accurately describe all properties simultaneously. Moreover, the representation of basic properties such as saturated pressure and density deteriorates with both models.

From the above results, we conclude that the methods using liquid density alone and derivative properties into the parameter estimation have not been very successful. Therefore, we focus again on an improvement - modification of the classical method. All HFOs considered are polar molecules, but it is unclear whether or not they can be considered associating molecules. Our 
models for HFOs do not include an explicit contribution for the polar interactions, thus we have assumed a two-site (2B) association scheme in method 2. This is inspired by other researchers who modeled strong polarity via association ${ }^{50,51}$. The \%AAD ${ }^{\text {all }}$ of CPA and PC-SAFT with method 2 are $3.6 \%$ and $2.7 \%$, indicating that CPA performs better than method 1 but PC-SAFT performs worse. For liquid density, vapor pressure and isobaric heat capacity, both models provide very good results. However, the performance of PC-SAFT in predicting speed of sound and isothermal compressibility deteriorates with deviations (with method 2) 11\% and 18\% compared to only 5\% and $9 \%$ with method 1 . When an association term is used, with both EoS additional parameters have to be determined. In order to perform a more complete evaluation of the parameter estimation methods, another eleven (11) methods are discussed. Nine (9) methods are using different combinations of different properties as those listed in Table 2, and the remaining two (2) methods are using 4C and 1A association schemes for the classic method (i.e. only vapor pressure and saturated liquid density in the objective function). The detailed results are presented in the Support Information (Tables S3-S9 and Figure S1). It can be seen from these results, on one hand, that the associating methods are able to accommodate more properties in the parameter fitting, which is expected as more parameters are involved. On the other hand, it is hard to conclude that using the association term the models will perform significantly better than the non-associating counterparts from an overall point of view for HFO pure compounds, especially for PC-SAFT. Regarding the association scheme, CPA performs best with 4C for all properties except the speed of sound in gas phase and the isobaric thermal expansivity, while PC-SAFT shows the best performance with 2B for heat capacity, 4C for all range of density data and speed of sound in liquid phase, and 1A for saturated pressure and density and other properties. A further study on the accuracy, efficiency and robustness of the effect of the association term on describing phase equilibria and properties 
of the HFO containing mixtures would be very much needed in order to make a thorough conclusion.

Maybe somewhat surprisingly, we found that upon replacing the saturated liquid density with liquid density under low pressure (method 3 ) results to very good $\% A A D^{\text {all }}$ values, $4.0 \%$ and $2.0 \%$ for CPA and PC-SAFT, respectively, including a good performance also for the derivative properties. At the same time, this method is to be preferred due to lack of plentiful experimental saturated liquid density data for these refrigerants. As a final note, in this comparative study of the CPA and PC-SAFT models in predicting primary and second-order derivative properties of HFOs, it can be concluded that CPA yields superior predictions for the isobaric heat capacity, but PCSAFT provides better speed of sound, isothermal compressibility and isobaric thermal expansivity predictions.

\section{Conclusion}

We have applied, in this work, the CPA and PC-SAFT EoS in a systematic way to a range of derivative properties of HFOs refrigerants. Eleven parameter estimation methods have been compared for both models, including the classical method with vapor pressures and saturated liquid densities (methods 1, 2), only density data used (methods 5, 6), introducing derivative properties (methods 7, 8, 9, 10,11) and replacement of saturated liquid density with liquid density under low pressure (method 3) as well as using all density data available (method 4). Comparisons were presented between calculated thermodynamic properties and data from literature as well as those extracted from the NIST database ${ }^{53}$. Generally, PC-SAFT yields better results (smaller percentage deviations) in correlating most of the second-order derivative properties containing speed of sound, isothermal compressibility and isobaric thermal expansivity. CPA performs better in predicting isobaric heat capacity. Considering a comparison of all eleven methods, the third 
method, namely applying vapor pressure and liquid density under low pressures (method 3), is recommended for HFOs considered, meeting both the convenience of use and accuracy of predictions. The total $A A D^{\text {all }}$ value of all thermodynamic properties considered for these HFOs with CPA and PC-SAFT using this method (method 3) are $4.0 \%$ and $2.0 \%$, respectively. Future research should focus on thermodynamic properties of blend refrigerants containing HFOs, which are important for industrial applications.

\section{AUTHOR INFORMATION}

\section{Corresponding Author}

* Tel.: +45 452528 77. E-mail address: xlia@kt.dtu.dk (Xiaodong Liang)

\section{ACKNOWLEDGMENT}

This work was supported by the National Natural Science Foundation of China (No. 51776170). The research of Kai Kang was supported by the China Scholarship Council (Grant No. 201706280283). 


\begin{abstract}
ABBREVIATIONS
EoS, equation (s) of state; CPA, cubic plus association; PC-SAFT, perturbed-chain statistical associating fluid theory; $\mathrm{AAD}$, average absolute deviation; $R$, gas constant; $T$, temperature; $P$, pressure; $V$, total volume; $u$, speed of sound; $C_{P}$, isobaric heat capacity, $A^{r}$, residual Helmholtz free energy; $m$, segment number; $x$, molar fraction; HVAC\&R, heating, ventilation, air conditioning, and refrigeration; ODP, ozone depletion potential; GWP, global warming potential; NIST, National Institute of Standard and Technology; HFCs, hydrofluorocarbons; HFOs, hydrofluoroolefins; SRK, Soave-Redlich-Kwong; $\kappa_{T}$, isothermal compressibility; $\alpha_{P}$, isobaric thermal expansivity; $W$, weighting factor; $N$, number of properties; $\rho$, molar density; $O F$, objective function; $V^{w}$, van der Waals volume.
\end{abstract}

\title{
Superscripts and Subscripts
}

hc, chain term of reduced residual Helmholtz free energy; disp, dispersion term of reduced residual Helmholtz free energy; assoc, association term of reduced residual Helmholtz free energy; $A_{i}$, association site index $A$ of component $i$; ig, ideal gas; sat, saturated; lp, low pressure; liquid, in liquid phase; all, all literature data available.

\section{Supporting Information}

The pure component CPA and PC-SAFT parameters including non-associating and associating parameters, and the $\% A A D$ from CPA and PC-SAFT with different methods. 


\section{REFERENCES}

(1) Kazakov, A.; McLinden, M. O.; Frenkel, M. Computational Design of New Refrigerant Fluids Based on Environmental, Safety, and Thermodynamic Characteristics. Industrial \& Engineering Chemistry Research 2012, 51 (38), 12537-12548.

(2) Di Nicola, G.; Fedele, L.; Brown, J. S.; Bobbo, S.; Coccia, G. Saturated Pressure Measurements of Trans-1-Chloro-3,3,3-Trifluoroprop-1-Ene (R1233zd(E)). Journal of Chemical and Engineering Data 2017, 62 (9), 2496-2500.

(3) Mondéjar, M. E.; Mclinden, M. O.; Lemmon, E. W. Thermodynamic Properties of Trans1-Chloro-3,3,3-Trifluoropropene $(\mathrm{R} 1233 \mathrm{zd}(\mathrm{E}))$ : Vapor Pressure, $(\mathrm{p}, \rho, \mathrm{T})$ Behavior, and Speed of Sound Measurements, and Equation of State. Journal of Chemical and Engineering Data 2015, 60 (8), 2477-2489.

(4) Meng, X.; Qiu, G.; Wu, J.; Abdulagatov, I. M. Viscosity Measurements for 2,3,3,3Tetrafluoroprop-1-Ene (R1234yf) and Trans-1,3,3,3-Tetrafluoropropene (R1234ze(E)). Journal of Chemical Thermodynamics 2013, 63, 24-30.

(5) Liu, Y.; Zhao, X.; Lv, S.; He, H. Isobaric Heat Capacity Measurements for R1234yf from 303 to $373 \mathrm{~K}$ and Pressures up to $12 \mathrm{MPa}$. Journal of Chemical and Engineering Data 2017, 62 (3), 1119-1124.

(6) He, Y.; Gao, N.; Jiang, Y.; Ren, B.; Chen, G. Isobaric Heat Capacity Measurements for Dimethyl Ether and 1,1- Difluoroethane in the Liquid Phase at Temperatures from $305 \mathrm{~K}$ to $365 \mathrm{~K}$ and Pressures up to $5 \mathrm{MPa}$. Journal of Chemical \& Engineering Data 2014, 59, $2885-2890$. 
(7) Tanaka, K.; Takahashi, G.; Higashi, Y. Measurements of the Vapor Pressures and p $\rho$ T Properties for Trans-1, 3, 3, 3-Tetrafluoropropene (HFO-1234ze (E)). J. Chem. Eng. Data 2010, 55 (6), 2169-2172.

(8) Kano, Y.; Kayukawa, Y.; Fujii, K.; Sato, H. Ideal-Gas Heat Capacity for 2,3,3,3Tetrafluoropropene (HFO-1234yf) Determined from Speed-of-Sound Measurements. International Journal of Thermophysics 2010, 31 (11-12), 2051-2058.

(9) Lago, S.; Albo, P. A. G.; Brignolo, S.; Nazionale, I. Speed of Sound Results in 2,3,3,3Tetrafluoropropene (R1234yf) and Trans-1,3,3,3-Tetrafluoropropene (R1234ze(E)) in the Temperatrue Range of (260 to 360) K. 2011, 161-163.

(10) Yin, J.; Zhou, Y.; Zhao, G.; Ma, S. Measurements of Vapor Pressure and Gaseous PvT Property for Trans-1,3,3,3-Tetrafluoropropene (HFO-1234ze(E)). Fluid Phase Equilibria 2018, 460, 69-74.

(11) Gong, M.; Zhang, H.; Li, H.; Zhong, Q.; Dong, X.; Shen, J.; Wu, J. Vapor Pressures and Saturated Liquid Densities of HFO1234ze(E) at Temperatures from 253.343 to 293.318 K. International Journal of Refrigeration 2016, 64, 168-175.

(12) Di Nicola, G.; Brown, J. S.; Fedele, L.; Bobbo, S.; Zilio, C. Saturated Pressure Measurements of Trans -1,3,3,3-Tetrafluoroprop-1-Ene (R1234ze(E)) for Reduced Temperatures Ranging from 0.58 to 0.92. Journal of Chemical and Engineering Data 2012, 57 (8), 2197-2202.

(13) Gao, N.; Chen, G.; Li, R.; Wang, Y.; He, Y.; Yang, B. Measurements of the Isobaric Heat Capacity of Pressurized Liquid Trans-1,3,3,3-Tetrafluoropropene [R1234ze(E)] by 
Scanning Calorimetry. Journal of Thermal Analysis and Calorimetry 2015, 122 (3), 14691476.

(14) Fedele, L.; Pierantozzi, M.; Di Nicola, G.; Brown, J. S.; Bobbo, S. Compressed Liquid Density and Vapor Phase PvT Measurements of Trans-1-Chloro-3,3,3-Trifluoroprop-1-Ene [R1233zd(E)]. Journal of Chemical and Engineering Data 2018, 63 (1), 225-232.

(15) Fedele, L.; Brown, J. S.; Di Nicola, G.; Bobbo, S.; Scattolini, M. Measurements and Correlations of Cis-1,3,3,3-Tetrafluoroprop-1-Ene (R1234ze(Z)) Subcooled Liquid Density and Vapor-Phase PvT. International Journal of Thermophysics 2014, 35 (8), 1415-1434.

(16) Lago, S.; Giuliano Albo, P. A.; Brown, J. S. Compressed Liquid Speed of Sound Measurements of Cis-1,3,3,3-Tetrafluoroprop-1-Ene (R1234ze(Z)). International Journal of Refrigeration 2016, 65, 55-59.

(17) Brown, J. S.; Di Nicola, G.; Fedele, L.; Bobbo, S.; Zilio, C. Saturated Pressure Measurements of 3,3,3-Trifluoroprop-1-Ene (R1243zf) for Reduced Temperatures Ranging from 0.62 to 0.98. Fluid Phase Equilibria 2013, 351, 48-52.

(18) Di Nicola, G.; Steven Brown, J.; Fedele, L.; Securo, M.; Bobbo, S.; Zilio, C. Subcooled Liquid Density Measurements and PvT Measurements in the Vapor Phase for 3,3,3Trifluoroprop-1-Ene (R1243zf). International Journal of Refrigeration 2013, 36 (8), 22092215.

(19) Fedele, L.; Di Nicola, G.; Brown, J. S.; Colla, L.; Bobbo, S. Mesures de La Pression de Saturation Du Cis-Pentafluoroprop-1-Ene (R1225ye(Z)). International Journal of Refrigeration 2016, 69, 243-250. 
(20) Cui, J.; Bi, S.; Meng, X.; Wu, J. Surface Tension and Liquid Viscosity of R32+R1234yf and R32+R1234ze. Journal of Chemical and Engineering Data 2016, 61 (2), 950-957.

(21) Liu, Y.; Zhao, X.; He, H.; Wang, R. Heat Capacity of R1234ze( E ) at Temperatures from 313 to $393 \mathrm{~K}$ and Pressures up to $10 \mathrm{MPa}$. Journal of Chemical \& Engineering Data 2018, $63(1), 113-118$.

(22) Perkins, R. A.; McLinden, M. O. Spherical Resonator for Vapor-Phase Speed of Sound and Measurements of 1,1,1,2,2,3,3-Heptafluoro-3-Methoxypropane (RE347mcc) and Trans1,3,3,3-Tetrafluoropropene [R1234ze(E)]. Journal of Chemical Thermodynamics 2015, 91, 43-61.

(23) Higashi, Y.; Sakoda, N.; Islam, M. A.; Takata, Y.; Koyama, S.; Akasaka, R. Measurements of Saturation Pressures for Trifluoroethene (R1123) and 3,3,3-Trifluoropropene (R1243zf). Journal of Chemical and Engineering Data 2018, 63 (2), 417-421.

(24) Romeo, R.; Giuliano Albo, P. A.; Lago, S.; Brown, J. S. Densités Liquides Expérimentales Du Cis-1,3,3,3- Tetrafluoroprop-1-Ene $(\mathrm{R} 1234 \mathrm{ze}(\mathrm{Z}))$ et Du Trans-1-Chloro-3,3,3Trifluoropropène (R1233zd(E)). International Journal of Refrigeration 2017, 79, 176-182.

(25) Liu, Y.; Zhao, X. Measurement of the Heat Capacity of R1233zd(E). International Journal of Refrigeration 2018, 86, 127-132.

(26) Fedele, L.; Bobbo, S.; Groppo, F.; Brown, J. S.; Zilio, C. Saturated Pressure Measurements of 2,3,3,3-Tetrafluoroprop-1-Ene (R1234yf) for Reduced Temperatures Ranging from 0.67 to 0.93. Journal of Chemical and Engineering Data 2011, 56 (5), 2608-2612.

(27) Richter, M.; McLinden, M. O.; Lemmon, E. W. Thermodynamic Properties of 2,3,3,3- 
Tetrafluoroprop-1-Ene (R1234yf): Vapor Pressure and p - $\rho$ - T Measurements and an Equation of State. Journal of Chemical and Engineering Data 2011, 56 (7), 3254-3264.

(28) Klomfar, J.; Součková, M.; Pátek, J. Liquid-Phase p - $\rho-$ T Data for 2,3,3,3-Tetrafluoroprop1-Ene (R-1234yf) and 1,1,2,3,3,3-Hexafluoroprop-1-Ene (R-1216) at Temperatures from (208 to 353) K under Pressures up to $40 \mathrm{MPa}$. Journal of Chemical and Engineering Data 2012, 57 (11), 3283-3289.

(29) Fedele, L.; Brown, J. S.; Colla, L.; Ferron, A.; Bobbo, S.; Zilio, C. Compressed Liquid Density Measurements for 2,3,3,3-Tetrafluoroprop-1-Ene (R1234yf). Journal of Chemical and Engineering Data 2012, 57 (2), 482-489.

(30) Lago, S.; Albo, P. A. G.; Brignolo, S.; Nazionale, I. Speed of Sound in 2,3,3,3Tetrafluoropropene (R1234yf) and Trans-1,3,3,3-Tetrafluoropropene (R-1234ze(E)) in the Temperature Range of (260 to 360 ) K. 2011, 161-163.

(31) Raabe, G.; Maginn, E. J. Erratum: Molecular Modeling of the Vapor-Liquid Equilibrium Properties of the Alternative Refrigerant 2,3,3,3-Tetrafluoro-1-Propene (HFO-1234yf) (The Journal of Physical Chemistry Letters (2010) 1 (93) DOI: 10.1021/Jz900070h). Journal of Physical Chemistry Letters 2010, 1 (18), 2675.

(32) Raabe, G.; Maginn, E. J. A Force Field for 3,3,3-Fluoro-1-Propenes, Including HFO1234yf. Journal of Physical Chemistry B 2010, 114 (31), 10133-10142.

(33) Raabe, G.; Maginn, E. J. Molecular Modeling of the Vapor-Liquid Equilibrium Properties of the Alternative Refrigerant 2,3,3,3-Tetrafluoro-1-Propene (HFO-1234yf). Journal of Physical Chemistry Letters 2010, 1 (1), 93-96. 
(34) Raabe, G. Molecular Simulation Studies on the Vapor-Liquid Phase Equilibria of Binary Mixtures of R-1234yf and R-1234ze(E) with R-32 and CO2. Journal of Chemical and Engineering Data 2013, 58 (6), 1867-1873.

(35) Lai, N. A. Thermodynamic Properties of HFO-1243zf and Their Application in Study on a Refrigeration Cycle. Applied Thermal Engineering 2014, 70 (1), 1-6.

(36) Lai, N. A. Equations of State for HFO-1234ze(E) and Their Application in the Study on Refrigeration Cycle. International Journal of Refrigeration 2014, 43, 194-202.

(37) Lai, N. A.; Phan, T. T. H. Review of the BACKONE Equation of State and Its Applications. Molecular Physics 2017, 115 (9-12), 1041-1050.

(38) Lai, N. A.; Vrabec, J.; Raabe, G.; Fischer, J.; Wendland, M. Description of HFO-1234yf with BACKONE Equation of State. Fluid Phase Equilibria 2011, 305 (2), 204-211.

(39) Fouad, W. A.; Vega, L. F. Next Generation of Low Global Warming Potential Refrigerants: Thermodynamic Properties Molecular Modeling. AIChE Journal 2018, 64 (1), 250-262.

(40) Gross, J.; Sadowski, G. Perturbed-Chain SAFT: An Equation of State Based on a Perturbation Theory for Chain Molecules. Industrial and Engineering Chemistry Research 2001, 40 (4), 1244-1260.

(41) von Solms, N.; Michelsen, M. L.; Kontogeorgis, G. M. Computational and Physical Performance of a Modified PC-SAFT Equation of State for Highly Asymmetric and Associating Mixtures. Industrial and Engineering Chemistry Research 2003, 42 (5), 10981105.

(42) Kontogeorgis, G. M.; Voutsas, E. C.; Yakoumis, I. V.; Tassios, D. P. An Equation of State 
for Associating Fluids. Industrial and Engineering Chemistry Research 1996, 35 (11), 4310-4318.

(43) Soave, G. Equilibrium Constants from a Modified Redlich-Kwong Equation of State. Chemical Engineering Science 1972, 27 (6), 1197-1203.

(44) Wertheim, M. S. Fluids with Highly Directional Attractive Forces. II. Thermodynamic Perturbation Theory and Integral Equations. Journal of Statistical Physics 1984, 35 (1-2), 35-47.

(45) Wertheim, M. S. Fluids with Highly Directional Attractive Forces. III. Multiple Attraction Sites. Journal of Statistical Physics 1986, 42 (3-4), 459-476.

(46) Brunswick, N. Fluids with Highly Directional Attractive Forces . IV . Equilibrium Polymerization. 1986, 42, 477-492.

(47) Georgios M. Kontogeorgis; K., F. G. Industrial Applications Thermodynamic Models for Industrial Applications From Classical and Advanced; John Wiley \& Sons Ltd Registered, 2010.

(48) Gregorowicz, J.; O’Connel, J. P.; Peters, C. J. Some Characteristics of Pure Fluid Properties That Challenge Equation-of-State Models. Fluid Phase Equilibria 1996, 116, 94-101.

(49) Peng, D. Y.; Robinson, D. B. A New Two-Constant Equation of State. Industrial and Engineering Chemistry Fundamentals 1976, 15 (1), 59-64.

(50) Swaminathan, S.; Visco, D. P. Thermodynamic Modeling of Refrigerants Using the Statistical Associating Fluid Theory with Variable Range. 1. Pure Components. Industrial and Engineering Chemistry Research 2005, 44 (13), 4798-4805. 
(51) Swaminathan, S.; Visco, D. P. Thermodynamic Modeling of Refrigerants Using the Statistical Associating Fluid Theory with Variable Range. 2. Applications to Binary Mixtures. Industrial and Engineering Chemistry Research 2005, 44 (13), 4806-4814.

(52) Michelsen, M.; Mollerup, J. Thermodynamic Modelling: Fundamentals and Computational Aspects, Second Edition; Tie-line Publications: Denmark, 2007.

(53) Lemmon E, Huber M, M. M. NIST Standard Reference Database 23: Reference Fluid Thermodynamic and Transport Properties-REFPROP, Version 9.1. Gaithersburg, MD: Standard Reference Data Program, National Institute of Standards and Technology, 2013.

(54) Mondejár, M. E.; McLinden, M. O.; Lemmon, E. W. Thermodynamic Properties of Trans1-Chloro-3,3,3-Trifluoropropene (R1233zd(E)): Vapor Pressure, (\$p\$, \$p\$, \$T\$) Behavior, and Speed of Sound Measurements, and Equation of State. J. Chem. Eng. Data 2015, 60, 2477-2489.

(55) Mondéjar, M. E.; Mclinden, M. O.; Lemmon, E. W.; Di Nicola, G.; Fedele, L.; Brown, J. S.; Bobbo, S.; Coccia, G.; Cui, J.; Bi, S.; et al. Saturated Pressure Measurements of 3,3,3Trifluoroprop-1-Ene (R1243zf) for Reduced Temperatures Ranging from 0.62 to 0.98 . Journal of Chemical and Engineering Data 2016, 57 (8), 1469-1476.

(56) McLinden, M. O.; Thol, M.; Lemmon, E. W. No Title. In Thermodynamic Properties of trans-1,3,3,3-Tetrafluoropropene (R1234ze(E)):Measurement of Density and Vapor Pressure and a Comprehensive Equation of State; International Refrigeration and Air Conditioning Conference, 2010.

(57) Holland, T. J. B.; Powell, R. An Improved and Extended Internally Consistent 
Thermodynamic Dataset for Phases of Petrological Interest, Involving a New Equation of State for Solids. Journal of Metamorphic Geology 2011, 29 (3), 333-383.

(58) Rowlinson, J. S.; Swinton, F. L. Liquids and Liquids Mixtures, Third Edition; Butterworth \& Co (Publishers) Ltd, 1982.

(59) Cerdeiriñ, C. A.; Tovar, C. A.; González-Salgado, D.; Carballo, E.; Romaní, L. Isobaric Thermal Expansivity and Thermophysical Characterization of Liquids and Liquid Mixturesy. Physical Chemistry Chemical Physics 2001, 3 (23), 5230-5236.

(60) Troncoso, J.; Bessières, D.; Cerdeiriña, C. A.; Carballo, E.; Romaní, L. Automated Measuring Device of (p, $\rho, \mathrm{T})$ Data: Application to the 1- Hexanol+n -Hexane System. Fluid Phase Equilibria 2003, 208 (1-2), 141-154. 


\section{Table of Content}

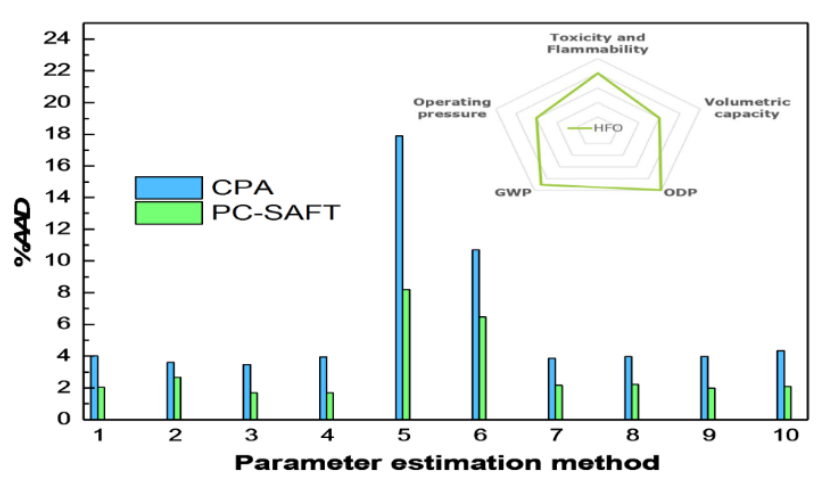

